v. 8 - n. 2- agosto-dezembro/2011 - ISSN: 1806-5023

\title{
ESTUDANTES NA RUA: INTERPRETANDO O CUNHO DEMOCRÁTICO DAS MANIFESTAÇÕES PELO TRANSPORTE PÚBLICO DE FLORIANÓPOLIS EM 2010 ${ }^{1}$
}

\author{
Fernanda Natasha Bravo $\mathrm{Cruz}^{2}$ \\ Cleber Jose Bosetti ${ }^{3}$ \\ Luciane Manika Espíndola ${ }^{4}$ \\ Nathália Schweder ${ }^{5}$ \\ Treicy Giovanella da Silveira ${ }^{6}$ \\ Aglaé Isadora Tumelero ${ }^{7}$ \\ Neivania Theodoro ${ }^{8}$
}

\section{INTRODUÇÃO}

Desde o momento em que Aristóteles no século IV a.C. escreveu sua obra "Política", na qual apresentou uma das primeiras tipologias das formas de governo, a teoria política passou a formular questionamentos e tentativas de respostas acerca da melhor forma de se governar uma sociedade. Daquele momento até hoje, as sociedades foram passando por substanciais transformações, elaborando diferentes respostas. O legado do século XX, com as

\footnotetext{
${ }^{1}$ Este artigo é resultante das atividades vinculadas ao "Minicurso de Teoria Política" organizado por bolsistas REUNI, alunos de pós graduação em Sociologia Política da Universidade Federal de Santa Catarina. O minicurso, voltado aos alunos de graduação em Ciências Sociais, foi oferecido entre maio de 2010 e junho de 2011. A revisão bibliográfica demonstrada contém questões tratadas durante o minicurso em encontros quinzenais entre os pós-graduandos e os graduandos. A pesquisa de campo foi realizada pelas alunas de graduação por meio de entrevistas qualitativas semi estruturadas nos meses de abril e maio de 2010, com participantes das manifestações em prol do transporte público em Florianópolis.

${ }^{2}$ Mestranda no Programa de Pós Graduação em Sociologia Política na UFSC. E-mail: fernandanatasha@gmail.com.

${ }^{3}$ Doutorando no Programa de Pós Graduação em Sociologia Política UFSC. E-mail:

cbbosetti@yahoo.com.br.

${ }^{4}$ Graduanda em Ciências Sociais UFSC. E-mail: nataliaschweder@gmail.com.

${ }^{5}$ Graduanda em Ciências Sociais UFSC. E-mail: Treyce.gs@gmail.com.

${ }^{6}$ Graduanda em Ciências Sociais UFSC. E-mail: aglae_t@hotmail.com.

${ }^{7}$ Graduanda em ciências sociais UFSC. E-mail: luhmanika@gmail.com.

${ }^{8}$ Graduanda em ciências Sociais UFSC. E-mail: nney_theodoro@hotmail.com.
}

(c) () EmTese by http://www.periodicos.ufsc.br/index.php/emtese/ind exis licensed under a Creative Commons Atribuição 3.0 Brasil 
experiências traumáticas dos Estados fascistas, levou o mundo ocidental a recuperar a democracia como a forma de governo considerada ideal. Podemos dizer que no cenário contemporâneo, o campo da teoria política apresenta uma dicotomia entre defensores de uma democracia de caráter mais procedimental e outra que tem na substancialidade da participação ${ }^{9}$ dos indivíduos seu elemento principal. A primeira decorre de uma visão mais descritiva e realista do processo democrático, enquanto a segunda possui um caráter mais normativo. Subjacentes a esta dicotomia, existem duas concepções fundantes de democracia: a democracia representativa e a democracia direta, que podem ser entendidas respectivamente, conforme apresentaremos neste artigo, como concepções restritas de democracia e concepções amplas de democracia.

De qualquer maneira, a operacionalização de uma forma democrática de governo está inextricavelmente ligada à instituição estatal. Falamos, então, em um Estado democrático por assim dizer, ou seja, as reflexões acerca da democracia no cenário contemporâneo dificilmente podem ser dissociadas do elemento Estado. Sabendo que este Estado, conforme nos indica Weber, é caracterizado por uma racionalidade própria, e que esta, não está necessariamente em conformidade com os interesses dos indivíduos. A democracia pode implicar em tensões entre o Estado e os indivíduos. Diante desta dualidade e das diferentes percepções de democracia presentes na teoria política contemporânea, nos propomos a analisar ${ }^{10}$ como estas

\footnotetext{
${ }^{9}$ É claro que esta divisão é apenas um recorte dado ao tema em função da delimitação analítica do artigo de dimensionar a relação entre o Estado e a sociedade acerca da democracia. Neste sentido, o critério da participação política permite discorrer teoricamente esta divisão. Porém, sabemos que há uma complexidade maior de concepções dentre os diversos modelos de democracia, ainda que nos restrinjamos neste aos modelos elitista, participativo e deliberativo.

${ }^{10}$ Neste artigo, realizamos entrevistas com estudantes participantes dos protestos, tanto oriundos do Movimento Passe Livre de Florianópolis (MPL), como do Diretório Central dos Estudantes da UFSC (DCE-UFSC) e também do movimento secundarista. Escolhemos estudantes para a amostra, porque, conforme os mesmos entrevistados e as reportagens do período, ainda que a Frente inclua associações de moradores, sindicatos, partidos políticos de esquerda e outras entidades, a grande maioria dos
} 
concepções distintas de democracia se fazem presentes no comportamento político que envolve a relação entre o Estado e a sociedade a partir de um conjunto de manifestações ocorridas na cidade de Florianópolis no ano de 2010. Estas manifestações foram realizadas como reação aos aumentos abusivos ${ }^{11}$ do preço dos passes de ônibus na cidade. No decorrer dos atos realizados, a forte repressão da polícia levantou dúvidas acerca da liberdade e dos direitos de expressão da participação política ${ }^{12}$ no Estado democrático. Temos por um lado, os manifestantes julgando estar exercendo uma forma de participação política democrática; por outro, o Estado, por meio da sua força policial, dando sinais de que havia uma ameaça à ordem estabelecida, deslegitimando o caráter da participação política democrática.

\section{A DEMOCRACIA COMO MÉTODO}

Tendo consciência da complexidade que envolve a concepção da democracia como método e da respectiva atribuição da mesma a um conjunto de pensadores denominados de elitistas, vamos aqui tão somente discorrer um panorama geral desta perspectiva. Neste sentido, buscamos tão somente referenciar como esta concepção de democracia concebe a participação social no processo político, a fim de relacionar empiricamente esta concepção com a atuação do Estado em relação às mobilizações na esfera pública, promovidas por

participantes das mobilizações era composta por estudantes.

${ }^{11} \mathrm{O}$ aumento das tarifas de ônibus em 2010 foi de 7,3\%, tendo o valor atingido R\$ 2,95 para os passageiros que não utilizassem de cartão transporte. Em 2009, a Gazeta do Povo (GARCIA, 2011) já noticiavam Florianópolis como o município portador da tarifa de ônibus urbano mais cara do país.

12 Uma forma corrente de compreender participação política é enquanto “[...] conjunto de ações e de comportamentos que aspiram a influenciar de forma mais ou menos direta e mais ou menos legal as decisões dos detentores do poder no sistema político ou em organizações políticas particulares, bem como a própria escolha daqueles, com o propósito de manter ou modificar a estrutura (e, consequentemente, os valores) do sistema de interesses dominante" (PASQUINO apud BORBA, 2010, p. 3). 
cidadãos dispostos a entrar na cena política sob o pretexto de estarem promovendo uma ação democrática e de direito.

A democracia concebida como método de escolha dos representantes está vinculada à concepção de democracia representativa. No cenário contemporâneo, uma corrente teórica que defende a concepção representativa, exaltando a dimensão procedimental da mesma, é parcialmente tributária de um conjunto de ideias elaboradas por pensadores do final do século XIX conhecidos como elitistas. A abordagem denominada de elitista parte do pressuposto de que a participação política no Estado democrático deve ser restrita ao processo eleitoral ${ }^{13}$ que define os representantes escolhidos pelo povo. Um dos argumentos dos teóricos elitistas baseia-se na teoria da irracionalidade das massas, onde a diluição do individuo num coletivo irracional limitaria sua capacidade de tomar decisões coletivas no campo da política, conforme pode ser observado em Pareto (1990).

Gaetano Mosca (1962), por sua vez, observa com restrição a participação da coletividade nos processos decisórios a partir de uma visão histórica. Em sua obra intitulada “História das Doutrinas Políticas", Mosca percorre as sociedades da antiguidade ao mundo moderno a fim de demonstrar que os Estados, independentemente da forma de governo, são constituídos por uma classe política, ou seja, uma elite de indivíduos. A formação desta elite envolve múltiplos fatores, desde econômicos, da tradição de algumas famílias e de aspectos intelectuais, este último em consonância com a ideia de irracionalidade das massas ${ }^{14}$. Nesta perspectiva, as sociedades

${ }_{13}$ Os pensadores elitistas deste período sequer viam com bons olhos o sufrágio universal, logo, qualquer forma de participação para além deste seria indiscutivelmente descartada pelos adeptos desta concepção de política restrita a um seleto grupo de indivíduos.

${ }^{14}$ É importante situar o contexto em que esta expressão foi cunhada. O século XIX, especialmente nos países industrializados da Europa, foi marcado por intensas agitações políticas. O desenvolvimento capitalista e a expansão da modernidade propriamente dita criaram o fenômeno das massas, ou seja, indivíduos que em função das circunstancias sociais se encontram deslocados, aglutinados, colocados em circulação num mesmo espaço. Esta aglutinação produz movimentos e ações 
sempre foram comandadas pela existência de governantes e governados, configurando a regra da minoria constituída por uma classe dirigente. Em se tratando das sociedades contemporâneas, onde o grau de complexidade e divisão do trabalho social ${ }^{15}$ foi estendido a limites extremos, os assuntos políticos também passaram a demandar de conhecimentos técnicos, da competência e disponibilidade para o exercício das atribuições que tal função demanda. Robert Michels (1982) estende esta perspectiva da participação aos partidos políticos. Conforme este autor, os partidos políticos, que em princípio eram um espaço de participação das massas, foram caminhando para um processo de oligarquização - ou seja, foram centralizando as decisões nas mãos de um grupo cada vez mais restrito de indivíduos. Conhecida como lei de ferro das oligarquias, a tese de Michels está baseada na incompetência das próprias massas no que tange a sua participação, demandando uma espécie de profissionalização dos políticos.

Os termos colocados pelos autores denominados de elitistas parecem ter inspirado outros autores no século XX. Temas como a racionalidade e a profissionalização no campo da política foram consagrados por autores como Max Weber (1979), quem classicamente concebeu o Estado como “[...] uma comunidade humana que, dentro de determinado território [...] reivindica 0 monopólio do uso legítimo da violência física". Nos domínios do Estado Moderno, a composição do político profissional cria uma distinção entre estes e os profissionais burocratas que prestam serviço no Estado. De qualquer forma, o princípio da divisão do mecânicas, muitas vezes impensadas e naturalizadas conforme o próprio ritmo da modernidade.

${ }^{15}$ Esta perspectiva de análise pode ser encontrada em Émile Durkheim, para o qual, nas sociedades complexas do mundo moderno, o Estado representa um grupo de pessoas que se distingue da massa. Logo, a democracia não significa a participação da coletividade na política, afinal, não é esta a função atribuída para a massa neste tipo de sociedade. Fazendo uma simplificação desta idéia, podemos entender que nas sociedades contemporâneas, a divisão do trabalho social também cria atribuições do ponto de vista político, delineando um grupo de indivíduos designados funcionalmente para exercer tais atribuições. 
trabalho social e da separação das massas da atividade política são elementos recorrentes nesta linha de autores citados.

Contudo, o formato de democracia no mundo contemporâneo apresenta-se formalmente como uma democracia representativa. Mais do que esta constatação trivial, há uma dimensão substancial envolvida neste conceito que consiste na proeminência do método sobre a participação do povo no processo político (embora isso não signifique a exclusão de toda e qualquer participação). Bobbio (2000, p. 372-373), ao estabelecer uma das diferenciações fundamentais entre a democracia dos antigos e a democracia dos modernos, ressalta que na primeira o valor primordial estava na participação do povo, sendo as eleições uma dimensão secundária; enquanto que a democracia moderna pode ser definida como um método para escolher representantes.

No campo da teoria democrática contemporânea, a observação deste estado de coisas foi elaborada por Joseph Schumpeter (1961). Para este autor, “[...] as grandes questões políticas tomam lugar na economia psíquica do cidadão típico lado a lado com os interesses das horas de lazer que ainda não se tornaram hobbies". Dessa forma, um arranjo democrático possível no mundo contemporâneo não poderia contar com uma forma de participação dos indivíduos ${ }^{16}$ nos moldes atenienses. Sendo assim, o arranjo eleitoral do voto livre tornou-se uma maneira pragmática e funcional de possibilitar aos cidadãos um momento de exercício de participação política.

Nesta perspectiva aberta por Schumpeter, a democracia perde o essencialismo idealista da ideia de participação dos indivíduos nos processos decisórios da política e torna-se um arranjo funcional para

\footnotetext{
${ }^{16}$ É importante lembrar que a utilização deste termo poder ser apropriada para o cenário contemporâneo, embora não seja adequada para referir-se à democracia grega onde a ideia de indivíduo era inexistente. Podemos inferir que esta dimensão que envolve o conceito de indivíduo na relação com a democracia pode ser uma chave explicativa para compreender o próprio funcionamento desta forma de governo. No entanto, tal argumentação exigiria um esforço analítico de caráter mais filosófico que escapa a alçada deste trabalho.
} 
se estabelecer procedimentalmente uma forma de democracia possível. Sob este viés, Schumpeter (1961, p. 328) afirma que “[...] o método democrático é um sistema institucional para tomada de decisões políticas, no qual o indivíduo adquire o poder de decidir mediante uma luta competitiva pelos votos dos eleitores". Claramente, há uma inversão da ideia de poder do povo em prol dos procedimentos. Assim, a quintessência democrática por excelência passa a ser identificada no momento das eleições. Bobbio (2000, p. 374) lembra que “[...] hoje a eleição é a regra e a participação direta a exceção, ou seja, a democracia de hoje é uma democracia representativa às vezes complementada por formas de participação popular direta".

Esta inversão implica que a ideia de poder do povo é transferida para um conjunto de representantes que passam a ocupar uma posição dentro do Estado. Estes formam uma espécie de elite política, ou seja, constituem um conjunto reduzido de indivíduos que estão ocupando uma posição diferenciada em relação aos demais e por isso exercem poder sobre o conjunto da população. Weber (1979, p. 5960) distinguiu que na emergência do Estado moderno e da burocracia que lhe é imanente, a política passou a ser vivida como uma atividade secundária pelos indivíduos e eleitores e como uma vocação por um grupo de profissionais que passaram a viver da política e para a política. Esta divisão pode ser percebida claramente na forma política representativa de democracia contemporânea. Neste sentido, a democracia nos Estados das sociedades contemporâneas preconiza a participação dos indivíduos como um mecanismo para escolher determinados representantes ou líderes, sendo que estes se tornam os responsáveis pelas decisões. A consequência disso é que o Estado passa a concentrar o poder e os mecanismos de dominação.

\section{UM ESBOÇO ÀS CONCEPÇÕES AMPLAS DE DEMOCRACIA}


As concepções de democracia apresentadas até agora podem ser compreendidas, aos olhos dos menos realistas, como antidemocráticas - ou, no mínimo, restritas. Entender a democracia enquanto método político de escolha de governantes corresponde a uma transparente contraposição à noção de democracia que remonta à polis ateniense, à compreensão de democracia enquanto "governo do povo". Se Aristóteles não foi um defensor tão ferrenho da democracia enquanto forma de governo ideal, preterindo-a pela aristocracia, muito tempo depois o desenvolvimento da história traz intelectuais que a recuperam e a entendem como forma ideal. No século XVIII, Rousseau é o grande expoente dessa abordagem e demonstra clara exaltação ao governo dos antigos (VIEIRA, 1997). Para Rousseau, democracia e representação não são compatíveis. O exercício da soberania pelo povo está em decidir suas próprias leis. A obediência da lei, nesse sentido, é uma obediência da própria vontade do povo, da vontade geral. Dessa forma, a vontade geral só pode ser expressa através da democracia direta e, portanto, não pode ser alienada, não é representável (WEFFORT et al, 2008; VIEIRA, 1997).

Em um ambiente democrático, a participação direta seria, conforme Rousseau, a única forma de realização da soberania do povo - uma vez que as outras formas de governo podem levar indivíduos governantes a se corromperem, fazendo do governo um mero atendente de seus interesses individuais, não o submetendo à vontade geral, mas sim às vontades particulares (WEFFORT et al, 2008; VIEIRA, 1997). Rousseau ${ }^{17}$ alerta para a possibilidade de constrangimentos que ricos podem causar aos pobres, minando a qualidade da participação. Então, uma forma de se permitir a participação direta e igualitária está em tratar a igualdade não

17 Uma limitação para a aplicação do projeto democrático de Rousseau é reconhecida por ele mesmo, quando expressa que tal ideal só pode ser atingindo em comunidades pequenas e as mais homogêneas possíveis (WEFFORT et al, 2008). 
somente em termos formais, como também em termos materiais (WEFFORT et al, 2008; VIEIRA, 1997).

Pode-se afirmar que o tratamento da democracia por Marx se dá na esteira de Rousseau, em especial devido ao ideal da igualdade material permear toda a obra marxiana. A pretensão de uma comunidade que supere o Estado, fundada em uma “livre associação de homens igualmente livres" (POGREBINSCHI, 2005, p. 3), embasa a sua concepção de democracia. É possível desvendar democracia em Marx ao compreendê-la, consoante a Engels, enquanto meio-termo entre as democracias grega, romana, americana e francesa, e ao compreender como exigir, como em Rousseau, que o homem não aliene suas liberdades econômicas ou políticas para realizar a democracia (POGREBINSCHI, 2005, p. 3). Menos do que as instituições, em Marx é a experiência humana que dá alicerce à democracia, sendo o Estado correspondente a somente um momento histórico da construção democrática, momento este que tenderia ao desaparecimento justamente com o aumento da democracia e com a consequente realização da emancipação humana e do comunismo (POGREBINSCHI, 2005, p. 6-7).

Entretanto, existe um ator em especial que é tratado por Marx e Rousseau de forma bastante diferente do que compreendemos contemporaneamente. Tal ator é fundamental para as reflexões atuais em torno da democracia, ainda que não haja consenso sobre sua conceituação. Referimo-nos aqui à sociedade civil. Em Rousseau, a sociedade civil seria constituída somente depois da firmação do contrato social, contrato este que deriva da igualdade e da participação de todos. Diferentemente em Marx, a sociedade civil estaria no plano da estrutura, compondo o todo complexo de relações materiais (BOBBIO, 1995) e em uma contraposição ao Estado, que estaria na superestrutura. De certa forma, a concepção contemporânea de sociedade civil está intimamente vinculada ao 
tema da democracia (ainda que não o determine), está distante de ambos autores, e agrega algo das perspectivas gramsciana (GRAMSCl, 1980) e da teorização habermasiana (HABERMAS, 1990) retrabalhada com nuances significativas por Cohen e Arato (2000), ainda que estas conceituações sejam distintas entre si e não encerrem o debate.

Gramsci, autor italiano que escreve em meados da década de 1920, possui diversos pontos em acordo com Marx e tem consigo o ideal revolucionário. Entretanto, dentre suas inovações ao marxismo, está assumir um deslocamento da sociedade civil da esfera da estrutura para a superestrutura. Tal deslocamento permite um afastamento da sociedade civil não só da economia, mas também do Estado (COHEN, ARATO, 2000) quando então cria uma dicotomia, na esfera superestrutural, entre poder ideológico e poder político, localizando a sociedade civil no âmbito do poder ideológico. É tal diferenciação analítica que vai permitir a ele seu desenvolvimento do conceito de hegemonia ${ }^{18}$. Há uma dialética entre sociedade política e sociedade civil que se manifestaria por meio da supremacia de um grupo social, seja ela exercida enquanto domínio e coerção, no caso da sociedade política, ou enquanto hegemonia e consenso, no caso da sociedade civil (COUTINHO, 1984, p.81). O projeto de Gramsci é construir a hegemonia a partir da fundação e organização de uma sociedade civil na qual os atuais grupos subalternos tenham adquirido consciência de sua força e das suas possibilidades, de seus modos de se desenvolver (GRAMSCl, 1966). A democracia, para este autor,

${ }^{18} \mathrm{Em}$ Gramsci, a hegemonia indica “[...] um sistema de alianças entre vários grupos, em que o grupo dominante exerce o poder graças à sua capacidade de transformar os interesses particulares em gerais ou universais" (FONTANA, 2001), interesses esses que não estão desvinculados da cultura, da ideologia e das visões de mundo dos atores. Para se realizar, a hegemonia leva também em conta os interesses e tendências dos grupos subalternos, exigindo equilíbrio de compromissos, sacrifícios por parte dos dirigentes (GRAMSCl, 1980, p. 33). Neste sentido, a hegemonia seria exercida na sociedade civil e consistiria na busca por aliados para sua posição por meio da direção e do consenso (COUTINHO, 1984, p. 79). 
pressupõe “[...] uma unidade orgânica entre teoria e prática, entre camadas intelectuais e massas populares, entre governantes e governados" (GRAMSCl, 1980, p. 84), uma tarefa de organismos bem constituídos a partir da sociedade civil, em um processo que ele denomina progresso histórico. A democracia só se realizaria plenamente no comunismo e, o autor concorda com Marx, com o fim da alienação política presente num Estado separado da sociedade.

Se em Gramsci o partido político possui o mais relevante papel na sociedade civil, em uma perspectiva mais contemporânea, a concretização da vontade coletiva pode ser percebida como derivada também de outros organismos. Há outros agentes da sociedade civil que também desempenham o papel de interlocutores entre os atores estatais e os atores econômicos, dentre eles os que são comumente chamados de movimentos sociais ${ }^{19}$. A concepção de sociedade civil mais corrente se pauta pela noção tripartite de sociedade (compreendendo sociedade civil, Estado e economia), e tem como referencial Cohen e Arato (2000). Ainda que conte com amplo suporte teórico e histórico, a maior influência para a teorização desses autores é, em última instância, a teoria da ação comunicativa habermasiana (HABERMAS, 1999a, 1999b).

Conforme Habermas, o locus da sociedade civil é o mundo da vida. O mundo da vida é o espaço social no qual a “[...] ação comunicativa permite a realização da razão comunicativa calcada no diálogo e na força do melhor argumento em contextos interativos, livres de coação" (FREITAG, 2005, p. 165). O conceito de sociedade, para este autor, é dual e compreende simultaneamente sistema e

${ }^{19}$ Ainda que possa ser dado algum destaque aos movimentos sociais, não se pode perder de vista que não só movimentos sociais de base (grassroot movements) compõem a sociedade civil. Se tomarmos a sociedade civil como espaço da sociedade simultaneamente distinto do Estado e da economia, podemos compreender que atores como partidos, igrejas, sindicatos e associações voluntárias a compõem e não se restringem ao nível nacional. É importante, entretanto, observar que retomada da discussão do conceito responde a dois fenômenos históricos: a recusa ao socialismo real na Europa Oriental e o embate contra os regimes militares na América Latina (SORJ, 2005). 
mundo da vida. O sistema, que é o espaço social da economia e do Estado, tem como princípio a eficiência, objetiva o dinheiro e o poder, e é orientado pela racionalidade cognitivo instrumental (HABERMAS, 1999b). Em sua teorização, Cohen e Arato reapropriam-se da teoria da ação comunicativa habermasiana para distinguir, no mundo da vida, duas dimensões distintas. A primeira seria ligada ao reservatório de tradições imersas na linguagem e na cultura. A segunda seria mais institucional, e incluiria as instituições e formas associativas que requerem a ação comunicativa para sua reprodução, e contam ainda com os processos de integração social para a coordenação da ação no interior de suas estruturas. A sociedade civil seria identificada na dimensão mais institucional do mundo da vida (AVRITZER, 1993). Habermas acata essa contribuição de Cohen e Arato para conceber uma sociedade civil com caráter duplo, ofensivo e defensivo, com relação à sua própria colonização pelo sistema - tomando-a enquanto instrumento contra a mercantilização e a burocratização das relações sociais (AVRITZER, 1993).

A teoria da ação comunicativa habermasiana compreende, em vários aspectos, a teoria social do mesmo autor (FREITAG, 2005). De certa forma, sua concepção de democracia está intimamente vinculada à ação comunicativa, correspondente a uma razão que é voltada ao entendimento mais do que ao êxito. Mais além, para ele, “[...] democracia é sinônimo de auto-organização política da sociedade" (HABERMAS, 1991:46). Sua perspectiva democrática enfatiza processos deliberativos, presentes em uma esfera pública informal na qual há debates sobre os valores e projetos da sociedade e é “[...] constituída por públicos culturalmente mobilizados nas associações da sociedade civil" (HABERMAS, apud FUNG, COHEN, 2007, p. 229). Tais processos são simultaneamente participativos na medida em que tratam das decisões políticas em associações 
secundárias ${ }^{20}$ e movimentos sociais, em uma tentativa de unir o ideal deliberativo ao participativo - lidando com a qualidade dos argumentos (ênfase da deliberação) e com a abrangência do número de pessoas envolvidas (ênfase da participação) (FUNG; COHEN, 2007). O alcance das decisões de uma discussão pública informal ocorre antes no âmbito público do que no âmbito político, sendo seu impacto político-institucional indireto (FUNG; COHEN, 2007). Ainda assim, “[...] à medida que o pensamento público livre molda a opinião e guia as decisões coletivas, a esfera pública deliberativa aumenta o auto-governo" (FUNG; COHEN, 2007, p. 229).

A complexidade das sociedades contemporâneas dificilmente poderia ser tratada por meio de uma nova polis que visasse corresponder à democracia direta rousseauniana, e as problemáticas experiências históricas do socialismo enfraqueceram politicamente quaisquer tentativas de concretização dos ideários marxistas. Conforme Santos e Avritzer (2002, p. 51), para ampliar a democracia e considerar o pluralismo é necessário criar uma nova gramática sociocultural, e procurar entender inovações sociais articuladas às institucionais. Dentro deste esboço de nova gramática sociocultural distinta daquela clássica, o discurso na esfera pública permite conectar procedimentalismo e participação (SANTOS, AVRITZER, 2002 , p. 53). Cabe acrescentar que a participação, menos do que rompe, agrega e enriquece a democracia representativa, ao se firmar no valor da legitimidade democrática. Mais além, as considerações sobre a participação se pautam pela ampliação ${ }^{21}$ da política, que estaria presente nas relações entre Estado e sociedade, e também dentro da própria sociedade nos mais diversos espaços sociais.

\footnotetext{
${ }^{20}$ As associações primárias, conforme Tocqueville (1987), referem-se à família. As associações secundárias são mais próximas daquelas que conhecemos enquanto associações de moradores, profissionais, etc.

${ }_{21}$ Pateman (1992), por exemplo, estuda o contexto participativo dentro de estruturas industriais.
} 


\section{DO PODER À VIOLÊNCIA}

Todo o poder emana do povo, que o exerce por meio de representantes eleitos ou diretamente, nos termos desta Constituição. (Constituição da República Federativa do Brasil de 1988. Artigo 1으).

Pelo que podemos observar até aqui, existem diferentes posicionamentos teóricos acerca da democracia no mundo contemporâneo. Em determinadas circunstâncias, estas diferentes concepções materializam-se numa espécie de tensão entre a esfera institucional representativa e a sociedade civil, principalmente quando esta procura ocupar o espaço da política e interferir na sua dinâmica. Tal tensão será observada neste trabalho através de uma manifestação ocorrida na cidade de Florianópolis no ano de 2010, onde as ruas foram novamente tomadas por estudantes ${ }^{22}$ devido ao descontentamento com 0 aumento das tarifas cobradas pelas empresas de ônibus da cidade.

Manifestações da sociedade civil em relação ao transporte público podem ser observadas desde os anos de 2004 e 2005 com as chamadas revoltas da catraca, as quais conseguiram barrar 0 aumento da tarifa do transporte coletivo de Florianópolis ${ }^{23}$. Naquele momento, as estratégias de ação dos militantes incluíam desde passeatas e panfletagem, até algumas ações pontuais mais radicais de depredação do patrimônio público. Ainda que as tarifas não tenham sofrido aumento, as ações mais radicais dos militantes não foram bem vistas pela opinião publica. Porém, no ano de 2010, novamente as tarifas sofreram aumentos considerados abusivos por parte de representantes da sociedade civil, o que gerou uma nova onda de manifestações que revelaram as fragilidades do sistema

\footnotetext{
${ }^{22}$ Isso porque movimentos semelhantes já haviam acontecido em anos anteriores, especialmente no ano de 2005, quando houve o maior movimento estudantil da cidade em decorrência dos aumentos dos preços das passagens na cidade de Florianópolis. O movimento que ficou conhecido como "revolta da catraca" levou milhares de jovens às ruas e foi marcado por conflitos entre os manifestantes e a polícia.

${ }^{23}$ Conforme melhor detalhado em Sousa (2005).
} 
democrático representativo e a tensão entre o Estado e a sociedade civil no que tange à participação democrática.

Nos relatos, era uníssona a dissociação feita entre o exercício do poder político e a qualidade da democracia. De certa forma, o poder político é entendido pelos entrevistados como exercido, no caso dos representantes do executivo e do legislativo, por quem está disposto a manter as coisas como estão - ou seja, não romper com o status quo de uma sociedade desigual, excludente e opressora. Ainda que haja quaisquer exceções, estas dentre representantes do legislativo de partidos de esquerda, estes poucos homens no poder institucional não teriam força política suficiente para desvincular os fortes laços entre poder econômico e poder político - falamos, em especial, do caso florianopolitano. De acordo com um militante do MPL,

\begin{abstract}
A prefeitura, a política que ela tem do transporte é a concessão. Então é pegar um serviço público e conceder para a iniciativa privada. A partir daí, todo o controle, toda a gestão do serviço está na iniciativa privada e vai seguir a lógica de empresa. Então, a tarifa serve para que os custos do transporte sejam remunerados [...]. Enfim, toda a lógica do transporte, do serviço público, passa para uma visão empresarial, para garantir o lucro das empresas [...]. E uma vez nas mãos deles, o contrato, fica aquele jogo, a prefeitura tem ligações muito fortes com o setor empresarial, com certeza, então os aumentos são cedidos e a população não é ouvida, não é estimulada a participar.
\end{abstract}

Ainda que o estopim que levou às mobilizações de maio de 2010 tenha sido o aumento na tarifa, o Movimento Passe Livre (MPL), um dos grupos que integra a Frente de Luta pelo Transporte Público de Florianópolis, congrega um ideal mais amplo, relacionado à mobilidade urbana, que há alguns anos transborda seu ideário fundante do passe livre estudantil para alcançar a proposta de um modelo de transporte público que seja efetivamente público, gratuito e de qualidade. Nesse sentido, tal compreensão de transporte público seria coerente com o tratamento dado pelo Estado à saúde ou à 
educação. Conforme outro militante, lutar pelo direito à mobilidade enquanto um direito transversal é importante porque

[...] a gente começa a ver o transporte como uma forma de controlar a cidade também, de segregação, porque tem lugares que não chega, ou apenas de manhã e à noite, pra levar e trazer os trabalhadores. É preciso fazer uma discussão do transporte como um direito que atravessa os outros direitos, por exemplo, pra chegar ao hospital, à escola, ao lazer precisa de transporte de alguma forma [sic].

Entretanto, um contexto de retraimento do Estado ${ }^{24}$ para ampliação do poder econômico complexifica não somente os alcances das políticas sociais, como também as discussões entre povo e Estado, em especial quando estas serviriam para passar por cima de interesses empresariais para atender às necessidades da população ainda mais por nos referirmos às necessidades de uma população de baixa renda. Ainda que haja espaços de discussão mais formais, abertos para a sociedade civil, tal abertura parece ser efetivamente fictícia. Em Florianópolis, há o Conselho Municipal de Transporte (CMT), que conforme seu regimento interno é um órgão consultivo e de deliberação coletiva sendo formado por um representante do órgão gestor, um representante do instituto de planejamento urbano, um representante do sindicato das empresas de transporte, um representante do sindicato de trabalhadores de transporte, um representante da câmara municipal e dois representantes da sociedade civil - da União Florianopolitana de Entidades Comunitárias $^{25}$ (UFECO). Entretanto, ainda que o conselho seja formalmente aberto à sociedade civil, as discussões sobre mobilidade pouco têm florescido nesse espaço participativo. De acordo com uma militante do DCE “[...] o CMT tem a participação popular mínima [...].

\footnotetext{
${ }^{24}$ Conforme, entre outros autores, Strange (2000).

25 De acordo com reportagem no Diário Catarinense em 14 de maio de 2010 (SERÁ,... 2010), a UFECO pertence à Frente de Luta pelo Transporte Público de Florianópolis.
} 
Tem uma hegemonia dos interesses das empresas de transporte" e, para esta estudante e militante do MPL,

[...] como a gente tá excluído de participar das decisões, no conselho de transporte a gente não tem voz, na câmara de vereadores a gente pressiona, mas eles votam segundo interesses deles. Então, a forma de participação democrática é na rua, nos atos, essa não institucional [sic].

Tomando em conta, para além dos relatos, os aumentos ${ }^{26}$ progressivos das tarifas dos ônibus em Florianópolis, a experiência de gestão participativa do conselho pode ser considerada pouco exitosa - não somente aos olhos dos entusiastas do passe livre, como também para os indignados com o valor da passagem. Uma alternativa democrática aos arranjos deliberativo-participativos é o protesto, ao menos conforme uma concepção mais ampla de democracia. Participar de manifestações tais como as passeatas e realizações de bloqueios de transito realizadas pela Frente, protestar, é uma atividade de participação política não convencional (BORBA, RIBEIRO, 2010).

Nesse sentido, a participação política, o exercício da democracia, extrapola não somente os meios convencionais que o cidadão tem para atuar politicamente, (o voto e as eleições), como também os meios institucionais de se atuar (como aquele no Conselho municipal). As manifestações podem visar realizar pressão política em torno de uma determinada demanda (no caso, a diminuição das tarifas de ônibus), mas não têm este fim exclusivo. Os eventos de protesto têm sido reconhecidos por estreitar laços sociais e serem pedagógicos e, conforme militante do DCE, os eventos de protesto contra a catraca em 2010 foram

[...] uma boa experiência da recuperação do poder por aqueles únicos que o detém [...]. O Movimento da

${ }^{26}$ Foi de em torno de $10 \%$ em 2010, o dobro da taxa de inflação e do aumento dos trabalhadores. 
Tarifa, pra mim, é um laboratório de perceber em que um setor da população consegue perceber que não basta confiar nos vereadores, naqueles inclusive em quem eles votaram, que aqueles não exercem o poder da maneira representativa (mandando obedecendo), e não resta outra alternativa que senão exercer o poder diretamente.[...] a única forma de falar de democracia, de representação real, é que as coisas caminhem nesse sentido, recuperar esse poder, esse "empoderamento" dos que detêm o poder de verdade, que só precisam se organizar e descobrir isso.

Diante deste quadro, o que podemos identificar é a existência de posicionamentos conflitantes entre a estrutura institucional do Estado e o ideário de representação democrático dos participantes dos movimentos no que tange à ideia de democracia. De um modo geral, os entrevistados enfatizaram a ideia de que a democracia de fato consiste na participação direta das pessoas na política, defendendo uma noção ampliada de democracia. A insatisfação com os representantes do poder público municipal, diante de sua conivência com os aumentos sucessivos nos preços das tarifas, levou os participantes do movimento a colocar em xeque a efetividade do formato representativo da democracia. Conforme um entrevistado:

A gente vive numa democracia mascarada. A questão da participação é totalmente maquiada, onde na política nossa participação se resume ao voto, onde de dois em dois anos a gente vota e pronto, elegemos nossos representantes e daí é com eles. E a partir disso, nossa representação é falha. A participação dos cidadãos nestes movimentos como o do transporte, põe a prova de que a democracia, não é somente esta democracia representativa legislativa que existe. $\mathrm{Na}$ democracia, existe outra forma de fazer política além do voto. No momento em que a democracia ou a política é falha, o cidadão tem não direito, mas o dever de ir pra rua e reivindicar seus direitos, que são legítimos [sic].

Neste sentido, o formato restrito de participação que opera no arranjo representativo é julgado como insuficiente para garantir o atendimento do interesse público. Afinal, no caso do transporte 
público de Florianópolis, as vias institucionais não estariam garantindo a substancialidade de tais interesses quando foram coniventes com os aumentos indiscriminados da tarifa. Isso incluía desde o executivo municipal, o legislativo e o próprio conselho municipal de transportes. A via mais autêntica de efetiva participação, na visão dos manifestantes, ocorria pelo protesto de rua através dos grupos organizados em movimentos sociais.

Se para alguns manifestantes a sensação de democracia direta, quase como de uma autonomia popular, foi marcante, para outros manifestantes, a experiência mais significativa dos eventos de 2010 foi aquela da violência. Conforme estudante da UFSC,

Muita gente foi presa. [...] eles prendiam, agrediam, empurravam, batiam, sabe. E toda uma pressão psicológica, a gente andava com muito medo porque eles vinham sem notificação, do nada aparecia o batalhão, ainda mais no centro, por que de repente não tinha ninguém, dali um pouco eles cercavam a gente, uns ataques surpresa, onde do nada eles apareciam e vinham para cima da galera com os cassetetes na mão. [...] O exemplo mais emblemático foi o episódio da UDESC [sic].

Mais uma vez, de acordo com um militante do MPL, vinte e cinco manifestantes foram presos. A impressão para ele era a de que as prisões tinham um sentido de ameaça, correspondiam a “[...] uma estratégia para assustar quem participa, para desestimular a participação[...]", visando no fundo “[...] causar um tumulto [...] para que as pessoas reajam com violência e que o movimento ganhe uma imagem de violento". Tais prisões eram curtas e os processos eram raramente encaminhados. O ato na UDESC, ou a invasão da UDESC pelos policiais militares foi "o exemplo mais emblemático" de violência policial que os manifestantes sofreram:

[...] esse ato na UDESC que foi, acho que a pior situação que passei na minha vida. De medo de ser preso, de sofrer violência. Prenderam pessoas 
arbitrariamente, um menino estava atravessando uma rua e derrubaram ele, deram choque, chutaram [...] A gente foi cerceado do direito de andar na calçada. A gente ia vir da UDESC pra cá, a gente ia voltar para a UFSC para se reunir e eles fizeram cordão na calçada, e a gente não podia passar [sic].

A forma de atuação da polícia era distinta daquela de protestos anteriores em Florianópolis, as marcadamente conhecidas revoltas da catraca, de 2004 e 2005. Conforme todos os entrevistados, o uso do taser, uma arma "não letal" usada para dar choques, era bastante comum. Muitas vezes, o cassetete e as balas de borracha deram lugar ao taser, que de acordo com uma estudante da UFSC, tem um impacto visual menor, gera menos revolta. Ainda assim, o medo da prisão e das armas, ainda que não-letais, era um torpe instrumento de mediação entre Estado e sociedade civil. O medo era o instrumento e o ator (que era o oposto de interlocutor, por emudecer antes de levar às vozes ao Executivo), era a Polícia Militar: “[...] o que o poder público, o que a prefeitura, coloca como meio de diálogo com a população é a repressão, é a força repressiva, é o braço armado, é a polícia".

A ação da polícia através das diversas formas de violência tinha as marcas da memória das manifestações de 2005. Em função disso, o movimento ocorrido em 2010 adotou outras estratégias de atuação a fim de melhorar sua aceitação perante a opinião publica e inibir a coerção policial. Dentre as novas estratégias adotadas, a arte e a cultura foram meios utilizados para sensibilizar a sociedade acerca dos problemas existentes em torno do transporte publico e do papel dos indivíduos enquanto agentes políticos. Conforme uma entrevistada vinculada ao DCE,

A gente conseguiu pautar muito forte a questão da arte e cultura dentro do movimento. A ideia de que você não chama as pessoas para participar assim no grito, é a diferença entre disputar a consciência e construir consciência, sabe? [sic] 
Dessa forma, os manifestantes realizaram vários atos como uma peça de teatro dentro do ônibus representando o enriquecimento dos donos das empresas de transporte e um jogo de futebol em que os cidadãos jogavam com as mãos amarradas enquanto os políticos e os empresários jogavam livremente. Essas estratégias foram, conforme estudantes entrevistados, recursos simbólicos utilizados pelos manifestantes para mostrar para a sociedade o descaso com que o executivo municipal estava tratando a questão do transporte público. Além disso, considerando a forma como as forças policiais estavam atuando para conter o movimento, que no caso de 2010 contava, para além da violência física, com a contenção da circulação dos manifestantes, as representações teatrais e artísticas não despertava atuação policial da mesma forma que outros atos de protesto, como passeatas, por exemplo. Contando com intenções e repertórios de ação variados, os estudantes mobilizados por muitas vezes sensibilizaram a população para o problema do transporte público do município. Entretanto, o objetivo fundante das mobilizações, que era minimamente o não-aumento das tarifas, não foi alcançado em 2010.

\section{CONSIDERAÇÕES FINAIS}

Os estudantes que protestaram nas ruas de Florianópolis revelaram uma tensão existente entre, por um lado, um Estado voltado à manutenção da ordem e de uma suposta segurança e, por outro lado, a busca por um Estado efetivamente pertencente a uma sociedade democrática - passando pela livre reivindicação da sociedade civil por direitos sociais. A fragilidade da democracia representativa e de seus aparatos institucionais, incluído neste caso as percepções em torno do Conselho Municipal de Transporte de Florianópolis, permitem-nos questionar o sentido público de um sistema representativo e pretensamente participativo, onde os 
interesses coletivos por vezes parecem estar carentes de uma representação efetiva.

Nesse sentido, as manifestações em prol do transporte coletivo em Florianópolis revelam a existência de uma tensão envolvendo diferentes acepções acerca da participação política dos indivíduos na democracia contemporânea. Por um lado, a ação do Estado, descrita como coercitiva, diante da presença dos cidadãos na rua ainda parece seguir os preceitos dos teóricos elitistas que alertavam para o perigo de massas irracionais na cena política. Por outro lado, a sociedade civil, descontente com o arranjo representativo no qual os interesses coletivos nem sempre são considerados, procura encontrar mecanismos de participação para corrigir deficiências do arranjo representativo de participação restrita.

De certa forma, os protestos e os intentos de participação nos processos decisórios, ainda que no caso descrito estivessem restritos à questão do transporte público de um município, descrevem pequenos traços de um esboço de construção democrática, isto se observarmos que a democracia não está plenamente estabelecida, podendo ser projetada em seu sentido mais amplo, abrangente e qualitativo.

\section{REFERÊNCIAS}

AVRITZER, L. Além da dicotomia estado/mercado: Habermas, Cohen e Arato. Novos Estudos Cebrap. São Paulo, n.36, p. 213-222, jul., 1993.

BOBBIO, Norberto. Teoria Geral da Política: A Filosofia Política e as Lições dos Clássicos. Rio de Janeiro: Elsevier, 2000.

BOBBIO, Norberto; MATTEUCCI, Nicola; PASQUINO, Gianfranco.

Dicionário de Política. 8a ed. Brasília: UnB. Vol.2. pp. 1207 - 1211. 1995.

BORBA, J. Participação política: uma revisão dos modelos de classificação. Mimeo, 2011. 
COHEN, Jean; ARATO, Andrew. Sociedad Civil y Teoría Política.

México, D.F. Fondo de Cultura Economica. 2000.

COUTINHO, Carlos Nelson. A democracia como valor universal. Rio de Janeiro: Salamandra, 1984.

DURKHEIM, Émile. Lições de Sociologia. São Paulo: Martins Fontes, 2002.

FREITAG, Bárbara. Dialogando com Jürgen Habermas. Rio de Janeiro: Tempo Brasileiro, 2005, p.161-188.

FUNG, A.; COHEN, J. Democracia radical. Política \& Sociedade, ago. 2008.

Disponível em:

http://www.periodicos.ufsc.br/index.php/politica/article/view/1293/121 $\underline{0}$. Acesso em 01 de agosto de 2010.

GARCIA, Euclides L. Curitiba tem a 5 a passagem mais cara entre capitais. Gazeta do Povo, 12 jan. 2009. Disponível em:

<http://www.gazetadopovo.com.br/vidaecidadania/conteudo.phtml? $\mathrm{tl}=1 \& \mathrm{id}=846189 \&$ tit=Curitiba-tem-5-tarifa-mais-cara-entre-capitais $>$. Acesso em 21 Ago. 2011.

GRAMSCl, Antonio. Concepção dialética da História. Rio de Janeiro: Civilização Brasileira, 1966.

GRAMSCl, Antonio. Maquiavel, a Política e o Estado Moderno. Rio de Janeiro: Civilização Brasileira, 1980.

HABERMAS, Jurgen. Teoría de la acción comunicativa I Racionalidad de la accion y racionalización social. Madrid: Grupo Santillana de Ediciones, S.A. 1999a.

HABERMAS, Jurgen. Teoría de la acción comunicativa II. Crítica de la razón funcionalista. Madrid: Grupo Santillana de Ediciones, S.A. 1999b. Interludio Segundo: Sistema y mundo de la vida. p. 161 - 280.

HABERMAS, Jurgen. Técnica e ciência como ideologia. Lisboa: Edições 70, 1991. p. 45-60.

MOSCA, Gaetano. História das Doutrinas Políticas. Rio de Janeiro: Zahar, 1962.

MICHELS, Robert. Sociologia dos Partidos Políticos. Brasília: UNB, 1982. 
PASSAGEM de ônibus em Florianópolis sobe 7,3\% e desagrada usuários. ClicRBS, Florianópolis, 07. mar. 2010. Disponível em: http:// www.clicrbs.com.br/diariocatarinense/jsp/default.jsp? $\underline{u f}=2 \&$ local $=18 \&$ section $=$ Economia\&news $I D=a 2896955 . h t m$. Acesso em 21 Ago. 2011.

POGREBINSCHI, Thamy. O enigma da democracia em Marx. Revista brasileira de ciências sociais, vol. 22, n. 63, 2007, p.55-67.

SANTOS, B. S. ; AVRITZER, L. Introdução: para ampliar o cânone democrático. In: SANTOS, B. S. Democratizar a democracia. Os caminhos da democracia participativa. Rio de Janeiro: Civilização Brasileira, 2002.

SCHUMPETER, Joseph. Capitalismo, Socialismo e Democracia. Rio de Janeiro: Fundo de Cultura, 1961.

SERÁ que eles conseguem? Diário Catarinense. Florianópolis, 14. Mar. 2010, p. 12.

SORJ, Bernardo. Sociedades Civis e Relações Norte-Sul: ONGs e Dependência. Biblioteca Virtual Marian e Arthur Edelstein, Centro Edelstein de Pesquisas Sociais. Working Paper 1, Rio de Janeiro, 2005 .

SOUSA, Janice Tirelli Ponte de. Juventude, contestação e a política de pernas para o ar: o Movimento Passe Livre em Florianópolis. Divulgação em rede. Anais do XXIV Congresso da ALASAssociação Latino Americana de Sociologia. Porto Alegre, julho de 2005. Disponível em: http://www.nejuc.ufsc.br. Acesso em 20 de março de 2011.

STRANGE, Susan. The retreat of the state: the diffusion of power in world economy. Cambridge, Londres, 2000.

VIEIRA, Luiz Vicente. A Democracia em Rousseau: a recusa dos pressupostos liberais. Porto Alegre: EDIPUCRS, 1997. 155p

TOCQUEVILLE, Alexis de. A democracia na América. Rio de Janeiro: Itatiaia, 1987.

WEBER, Max. Ensaios de Sociologia. Rio de Janeiro: Zahar, 1979.

WEFFORT, Francisco C. Os Clássicos da política : Maquiavel, Hobbes Locke, Montesquieu, Rousseau, "o federalista". 15. ed. São Paulo: Atica, 2008 


\section{RESUMO}

Em maio de 2010, a Frente de Luta pelo Transporte Público de Florianópolis, que conta com mais de quarenta grupos da sociedade civil do município, mobilizou mais de cinco mil pessoas entre passeatas e atos simbólicos constituídos em torno da insatisfação com o aumento da tarifa do transporte coletivo. Partindo de um delineamento sumário de conceitos de democracia bastante consolidados na literatura, serão interpretadas quais concepções de democracia a que se referem os manifestantes dos eventos de protesto compostos pela Frente e, por outro lado, quais teorias democráticas se aproximam do tratamento do Estado às mesmas manifestações. As relações entre Estado e sociedade civil, que por vezes tiveram a violência policial como mediadora, foram observadas fundamentalmente a partir de relatos de manifestantes.

PALAVRAS-CHAVE: democracia, transporte público, protesto.

\section{ABSTRACT}

In May 2010, the Front of Struggle for Public Transportation from Florianópolis (Frente de Luta pelo Transporte Público de Florianópolis), which has more than forty civil society groups in the city, has mobilized more than five thousand people to do parades and symbolic acts constituted around the dissatisfaction with the increased rate of public transportation. Beginning with a summary design of consolidated concepts of democracy in the literature, will be interpreted conceptions of democracy which referred to the protest events ruled by the front and, on the other hand, democratic theories which approach the treatment of manifestations by the State. Those relations between State and civil society, which sometimes had the police violence as a mediator, were observed through the narratives of protesters.

KEYWORDS: democracy, public transportation, protest. 